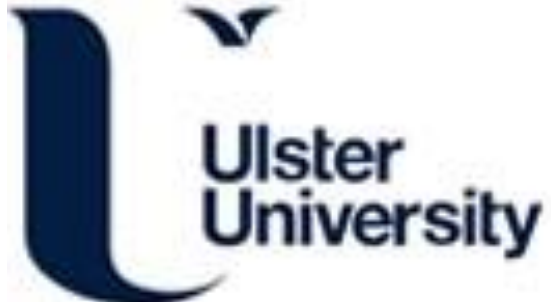

\section{The evaluation of an open source online training system for teaching 12 lead electrocardiographic interpretation}

Breen, C. J., Zhu, T., Bond, R., Finlay, D., \& Clifford, G. (2016). The evaluation of an open source online training system for teaching 12 lead electrocardiographic interpretation. Journal of Electrocardiology, 49(3), 454-461. https://doi.org/10.1016/j.jelectrocard.2016.02.003

Link to publication record in Ulster University Research Portal

\section{Published in:}

Journal of Electrocardiology

Publication Status:

Published (in print/issue): 14/03/2016

DOI:

10.1016/j.jelectrocard.2016.02.003

\section{Document Version}

Author Accepted version

\section{General rights}

Copyright for the publications made accessible via Ulster University's Research Portal is retained by the author(s) and / or other copyright owners and it is a condition of accessing these publications that users recognise and abide by the legal requirements associated with these rights.

\section{Take down policy}

The Research Portal is Ulster University's institutional repository that provides access to Ulster's research outputs. Every effort has been made to ensure that content in the Research Portal does not infringe any person's rights, or applicable UK laws. If you discover content in the Research Portal that you believe breaches copyright or violates any law, please contact pure-support@ulster.ac.uk. 


\section{Accepted Manuscript}

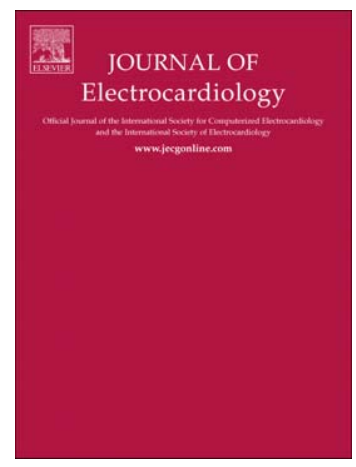

The evaluation of an open source online training system for teaching 12 lead electrocardiographic interpretation

Cathal Breen BSc Hons, Tingting Zhu MSc, Raymond Bond PhD, Dewar Finlay PhD, Gari Clifford PhD

PII: $\quad$ S0022-0736(16)00058-3

DOI: $\quad$ doi: $10.1016 /$ j.jelectrocard.2016.02.003

Reference: $\quad$ YJELC 52179

To appear in: $\quad$ Journal of Electrocardiology

Please cite this article as: Breen Cathal, Zhu Tingting, Bond Raymond, Finlay Dewar, Clifford Gari, The evaluation of an open source online training system for teaching 12 lead electrocardiographic interpretation, Journal of Electrocardiology (2016), doi: $10.1016 /$ j.jelectrocard.2016.02.003

This is a PDF file of an unedited manuscript that has been accepted for publication. As a service to our customers we are providing this early version of the manuscript. The manuscript will undergo copyediting, typesetting, and review of the resulting proof before it is published in its final form. Please note that during the production process errors may be discovered which could affect the content, and all legal disclaimers that apply to the journal pertain. 
Title: The evaluation of an open source online training system for teaching 12 lead electrocardiographic interpretation.

Cathal Breen BSc Hons(1), Tingting Zhu MSc (2), Raymond Bond PhD (3), Dewar Finlay PhD (4), Gari Clifford PhD (5).

(1) School of Health Sciences, University of Ulster, Shore Road, Newtownabbey, N. Ireland, BT37 0QB. Email: cj.breen@ulster.ac.uk

(2) Institute of Biomedical Engineering, Department of Engineering science, University of Oxford, Oxford, UK. Email: tingting.zhu@eng.ox.ac.uk

(3) School of Computing and Mathematics, University of Ulster, Shore Road, Newtownabbey, N. Ireland, BT37 0QB. Email: r.bond@ulster.ac.uk (4) School of Engineering, University of Ulster, Shore Road, Newtownabbey, N. Ireland, BT37 0QB. Email: d.finlay@ulster.ac.uk

(5) Depts. of Biomedical Informatics \& Biomedical Engineering, Emory University \& Georgia Institute of Technology Email: gari@gatech.edu Corresponding author: Cathal J. Breen. School of Health Sciences, University of Ulster, Shore Road, Newtownabbey, N. Ireland, BT37 0QB. Telephone: 00442890366860. Email: cj.breen@ulster.ac.uk

Disclaimer: I can confirm that the views expressed in this submitted article are our own and not an official position of the institution or funder. The software implementation of the open source online system for 12-lead ECG interpretation in this study is a customised version of CrowdLabel, which were both created and developed by Tingting Zhu, based on the Open Source LightWave Software created 
by George Moody. The design of the ECG interpretation was through consultation by Cathal J. Breen.

\section{Structured abstract:}

Introduction: The aim of this study is to present and evaluate the integration of a low resource JavaScript based ECG training interface (CrowdLabel) and a standardised curriculum for self-guided tuition in ECG interpretation.

Methods: Participants practiced interpreting ECGs weekly using the CrowdLabel interface to assist with the learning of the traditional didactic taught course material during a 6 week training period. To determine competency students were tested during week 7.

Results: A total of 245 unique ECG cases were submitted by each student. Accuracy scores during the training period ranged from $0-59.5 \%$ (median $=33.3 \%$ ). Conversely accuracy scores during the test ranged from $30-70 \%$ (median $=37.5 \%$ ) $(p<0.05)$. There was no correlation between students who interpreted high numbers of ECGs during the training period and their marks obtained.

Conclusions: CrowdLabel is shown to be a readily accessible dedicated learning platform to support ECG interpretation competency.

Key words: E Learning, ECG, Pedagogy, Assessment, Healthcare Science. 
Title: The evaluation of an open source online training system for teaching 12-lead electrocardiographic interpretation.

Disclaimer: I can confirm that the views expressed in this submitted article are our own and not an official position of the institution or funder. The software implementation of the open source online system for 12-lead ECG interpretation in this study is a customised version of CrowdLabel, which were both created and developed by XXXX, based on the Open Source LightWave Software created by George Moody. The design of the ECG interpretation was through consultation by $\mathrm{XXXX}$. 


\section{Structured abstract:}

Introduction: The aim of this study is to present and evaluate the integration of a low resource JavaScript based ECG training interface (CrowdLabel) and a standardised curriculum for self-guided tuition in ECG interpretation.

Methods: Participants practiced interpreting ECGs weekly using the CrowdLabel interface to assist with the learning of the traditional didactic taught course material during a 6 week training period. To determine competency students were tested during week 7.

Results: A total of 245 unique ECG cases were submitted by each student. Accuracy scores during the training period ranged from $0-59.5 \%$ (median $=33.3 \%$ ). Conversely accuracy scores during the test ranged from $30-70 \%$ (median $=37.5 \%)$ $(p<0.05)$. There was no correlation between students who interpreted high numbers of ECGs during the training period and their marks obtained.

Conclusions: CrowdLabel is shown to be a readily accessible dedicated learning platform to support ECG interpretation competency.

Key words: E Learning, ECG, Pedagogy, Assessment, Healthcare Science. 


\section{Introduction}

The electrocardiogram (ECG) is an important diagnostic tool in the detection of cardiac disease (1). Correct interpretation of an ECG contributes to the treatment and management of patients with cardiac disorders, specifically when diagnosing cardiac arrhythmias and acute myocardial ischaemic syndromes, which account for the majority of admissions to hospital (2).

Competency in interpreting an ECG is an important core area of undergraduate and postgraduate clinical training. The American College of Cardiology (ACC), the American Heart Association (AHA), and the Heart Rhythm Society (HRS) have together provided recommendations for standardizing and interpreting the ECG (38) providing curricula for academic institutions who educate healthcare professionals in using electrocardiography within different clinical settings.

Nevertheless, inaccurate ECG interpretation may lead to adverse patient outcomes (9). Despite their widespread clinical use, several studies have highlighted deficiencies in ECG interpretation among health professionals (10 -14). ECG interpretation is traditionally taught at medical school in the form of didactic teaching and self-study, though time allocation, faculty training and teaching format vary considerably (2). Mastering its interpretation requires considerable time and effort (9). ECG interpretation has traditionally relied on learners interpreting a target number of ECGs, however the number of ECG-examples needed to be interpreted to learn and maintain ECG competence is still unknown. For example in the Clinical Competence Statement on Electrocardiography from the American College of Cardiology and the American Heart Association (7) a total number of 500 ECG's is demanded to learn ECG-interpretation and 100 ECG's yearly to maintain ECG interpretation skills, conversely the recent COCATS 4 Task Force 3 : 
Training in Electrocardiography, Ambulatory Electrocardiography and Exercise Testing training statement (2) suggests interpreting approximately 3,000 to 3,500 ECGs within 36 months should provide ample experience to acquire competency in this clinical skill.

Clinical tutors, have difficulties in meeting these demands due to the shortening of time available to teach the medical curriculum and the expanding knowledge, and incorporation of new educational modules aiming to a broader competence, thus alternative ways to learn ECG interpretation are needed (16).

Education offered via the Internet, commonly referred to as electronic or e-learning is common place in academia. Such delivery is readily available, geographically independent (except in very remote regions) and flexible in terms of scheduling (17). Learning programmes that use the Web offer students more opportunities to learn at their own pace outside conventional working times, thereby reducing travel time and costs. Students have perceived that Web based learning tools provided an opportunity for improvement of self-analysis and critical thinking, as well as for sharing information with peers (18). However, disadvantages of online courses have also been reported, including sense of isolation and loss of personal interaction, absence of visual cues, and lack of face-to-face interaction (17-18). Hybrid approaches, combining face-to-face tuition with electronic resources, perhaps offers the best approach.

The aim of this study is to present and evaluate the integration of a low resource JavaScript based ECG training interface (a customised version of CrowdLabel (20)) and a standardised curriculum (19) for self-guided tuition in ECG diagnosis. The system was evaluated with a group of fifteen Healthcare Science Practitioner (HCSP) students studying an introductory module of electrocardiography over a 
period of one teaching term (twelve weeks). All students were recently educated to 2nd year undergraduate university level in a medical- related discipline as part of their university undergraduate degree course. HCSP's within the UK have expertise in applied scientific techniques within cardiac physiology and work in a healthcare setting, with a clearly defined technologically based role in the delivery and technical reporting of quality assured tests, investigations and interventions for patients (20).

\section{Methods}

The CrowdLabel annotation system is a derivative development from LightWAVE version 0.38 (21). It consists of a user authentication interface, a LightWAVE client, a back-end server database that mirrors PhysioBank (22) (an open data repository of freely available physiological data, including 12-lead ECGs) and 12-lead ECGs from ECG Eave-Maven (23). A local server that stores annotations provided by users (see Figure 1) is also included. CrowdLabel is a standalone platform which was developed using the HyperText Preprocessor (PHP), HyperText Markup Language version 5 (HTML5), JavaScript, JQuery, JQuery User Interface, and Scalable Vector Graphics (SVG). The configuration of the back-end server follows LightWAVE's infrastructure, which utilises a common gateway interface application to retrieve data from local data repository (including PhysioBank and private databases) and delivers them dynamically upon request generated by the LightWAVE client. The user authentication interface and the LightWAVE client can run within any modern web browser and does not require installation on the user's computer. The user interface of the web platform can be seen in Figure 1. See Zhu et al. (21) for further details. 


\section{Recruitment:}

HCSP students enrolled on module Cardiac Physiology 1 Electrocardiography within the BSc Hons Healthcare Science (CVRS) degree programme (Module Coordinator: Cathal Breen) were invited to partake in the study. An invitation poster advertising the research study was uploaded to the institutional virtual learning environment (Blackboard Learn) whereby students individually log in to access all digital aspects of their modules. Students registered their interest in participating in the study through e mail. Individual sign in credentials to access the Crowdlabel interface were provided following consent. The principal learning outcome of this module is 12-lead ECG interpretation in accordance to a national UK curriculum (19) delivered traditionally through didactic lectures ( 2 hours per week) and small group practical formats (2 hours per week).

\section{Study design:}

Participants were required to interpret ECG tracings using the CrowdLabel ECG training interface. The program prompts users to consider each element of the ECG tracing and determine which arrhythmia(s) are possible outcomes through the use of an analytic framework involving careful scrutiny of key variables (24). Analytic frameworks are lists of key variables to be sequentially considered. For ECGs, a common analytic framework is to examine the tracing to evaluate rate, rhythm, axis, chamber hypertrophy, signs of ischaemia, and timing intervals in a systematic fashion (25). For this study, we have designed an ECG report according to the teaching criteria offered in the module. The detail of the report is shown in Figure 2. 


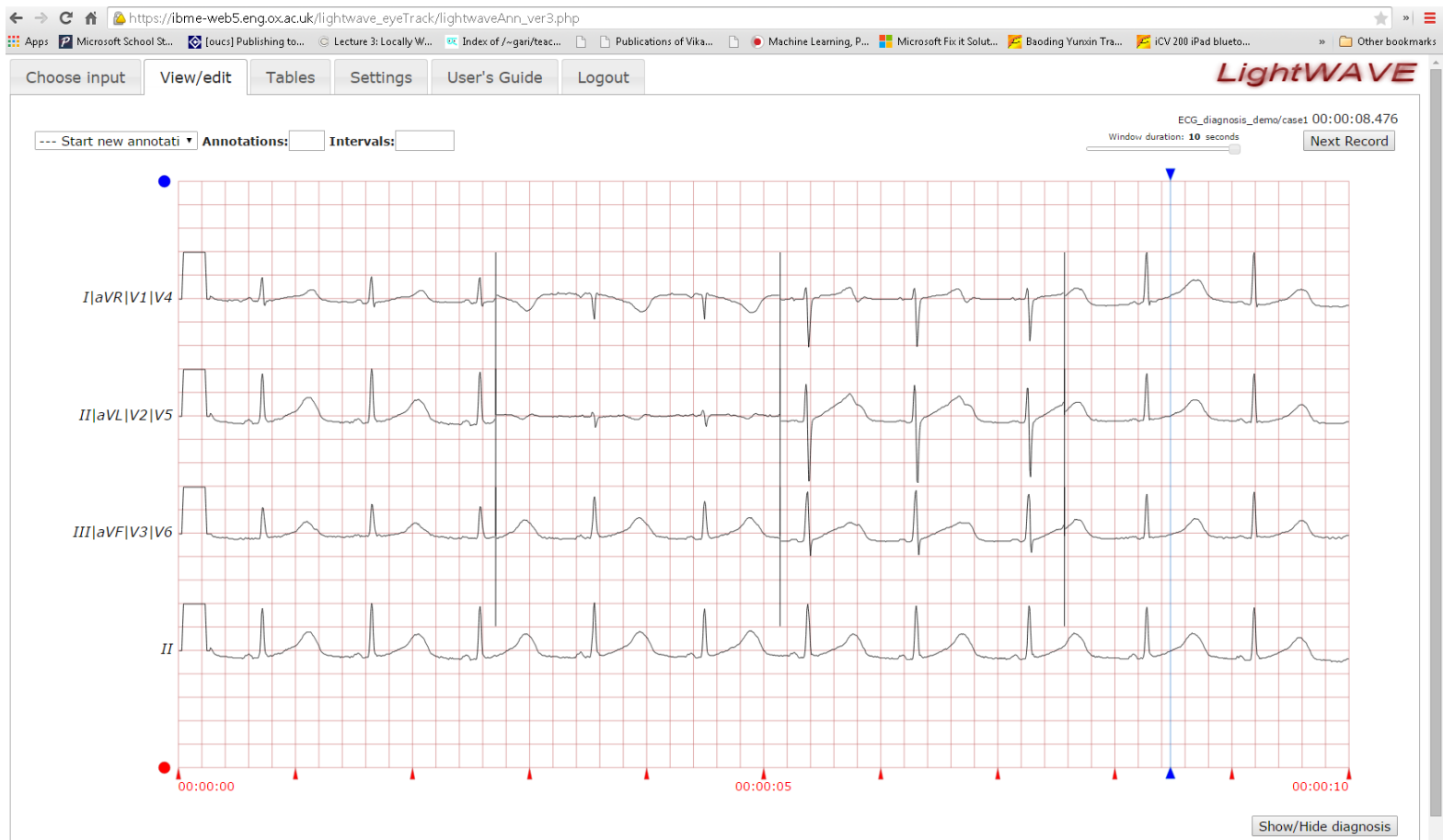

Figure 1: A screenshot of the CrowdLabel interface for displaying a 12-lead ECG.

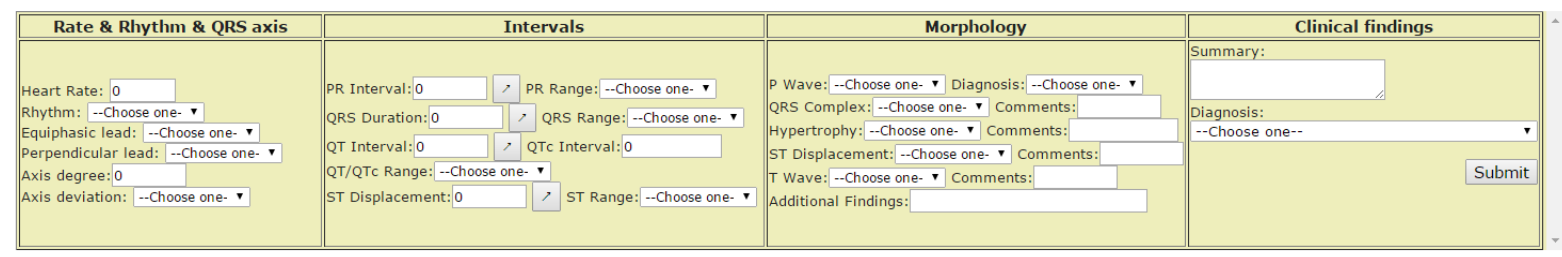

Figure 2: An ECG report designed according to the teaching criteria provided by the module Cardiac Physiology 1 Electrocardiography within the BSc (Hons.) Healthcare Science (CVRS) degree programme at Ulster University.

A total of 480 12-lead ECGs with gold standard diagnoses from additional diagnostics are available from this CrowdLabel ECG training interface source. A total of 10 cases, relevant to the training content within a given week, were chosen based on 13 ECG interpretation themes (table 1a). When a user chooses a case from one of these themes, CrowdLabel randomly selects from the pool of possible candidates and presents it to the user. The ECGs incorporated within this study were chosen based on the inclusion and illustration of precise electrical 
abnormalities in a unique or combined format aligning to the curriculum (19) and learning content delivered in a given week of the training period (weeks 1-6) and were consensually agreed appropriate by the teaching faculty who has expertise in clinical education and electrophysiology (table $1 \mathrm{~b})$.

Table 1a. A table illustrating the ECG interpretation themes

\begin{tabular}{|l|l|}
\hline $\begin{array}{l}\text { Schedule } \\
\text { (week) }\end{array}$ & ECG Themes \\
\hline 1 & Normal ECG \\
\hline 2 & Atrial dilatation and ventricular hypertrophy \\
\hline 3 & Axis deviation, fascicular block and bundle branch block, pre excitation \\
\hline 4 & Ventricular arrhythmias, junctional rhythms \\
\hline 5 & Atrial arrhythmias, AV Blocks \\
\hline 6 & Myocardial Ischaemia and infarction \\
\hline
\end{tabular}

Table 1b. A description of the selection and sequencing of the ECGs for inclusion to this study.

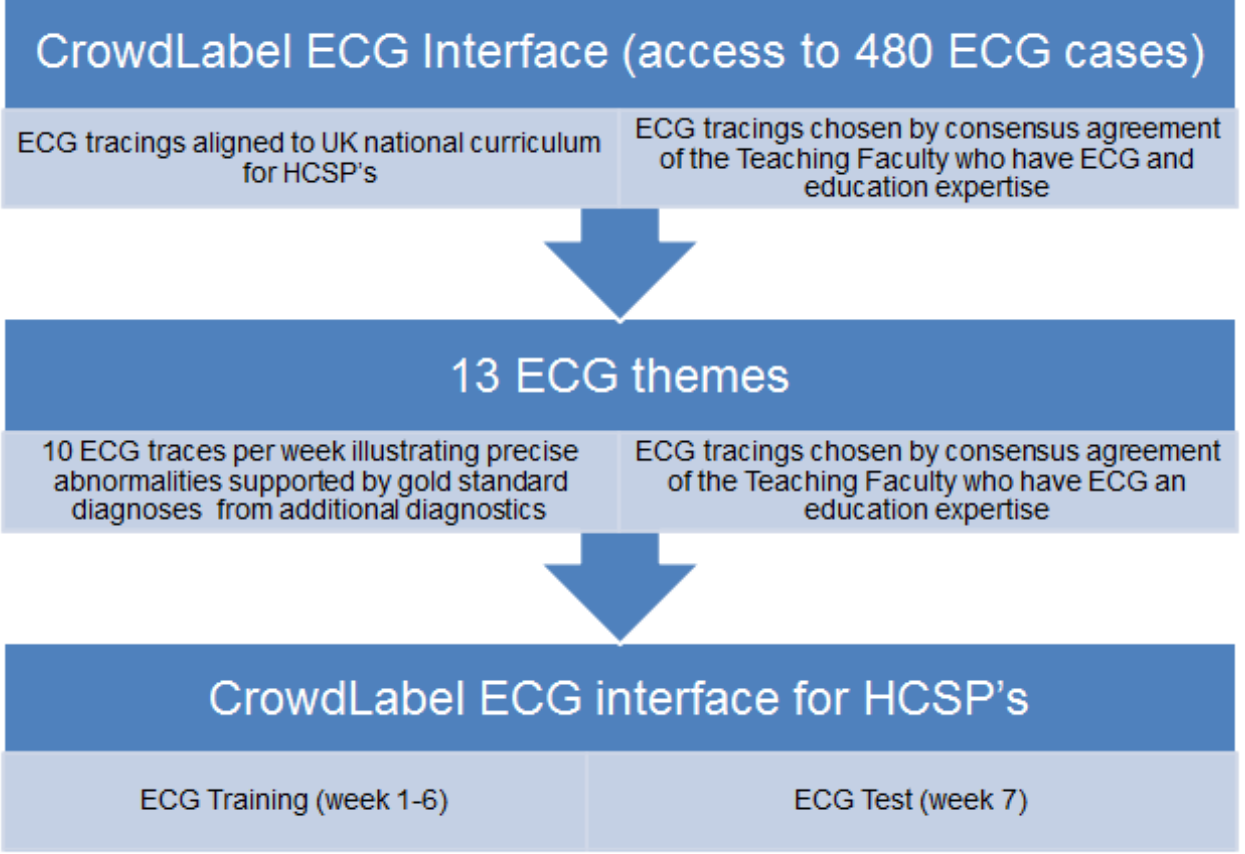


A prospective observational trial design was adopted for this study. A total of 17 students were recruited (participation rate $=88 \%$ ); Two students (number 11 and number 17) dropped out of the course and hence only 15 students, 5 male and 10 female (19-31 years old), enrolled to the web interface. All students were instructed in the use of the CrowdLabel interface and asked to practice interpreting ECGs weekly in this format to assist with the learning of the traditional taught course material. In order to evaluate students' performance of ECG interpretation we have divided weeks 1 to 6 of the term as the training period, charting the progress of a learner with ECG interpretation, with a test scheduled during week 7 to determine competency. The CrowdLabel interface is interactive and requires the student to annotate measurements of waveform duration and highlight these measurements to support an interpretation and eventual diagnosis. The interface allows users to zoom into a specific area of an ECG in a record, and label an interval directly as shown in Figure 3.

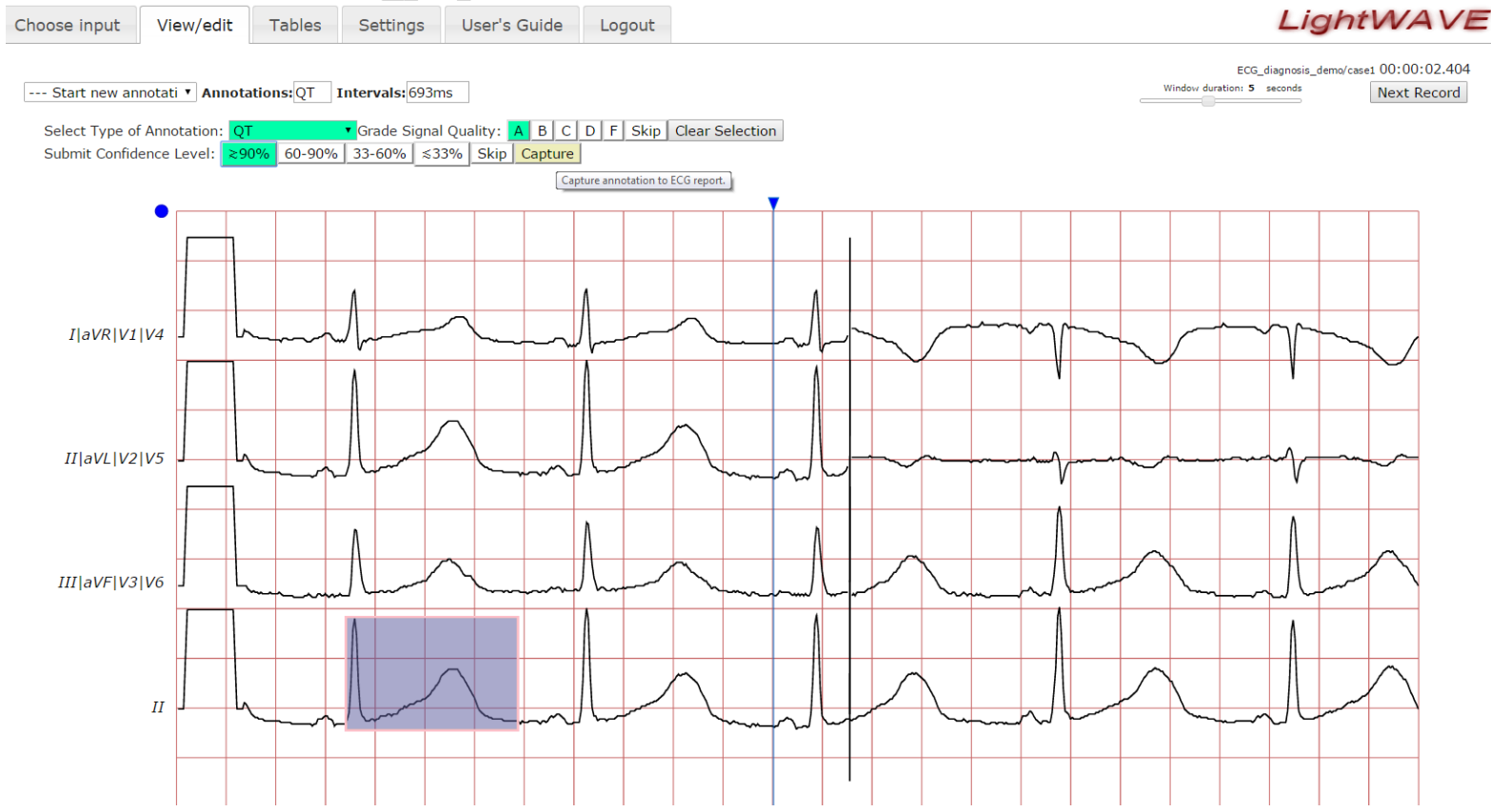

(a) 


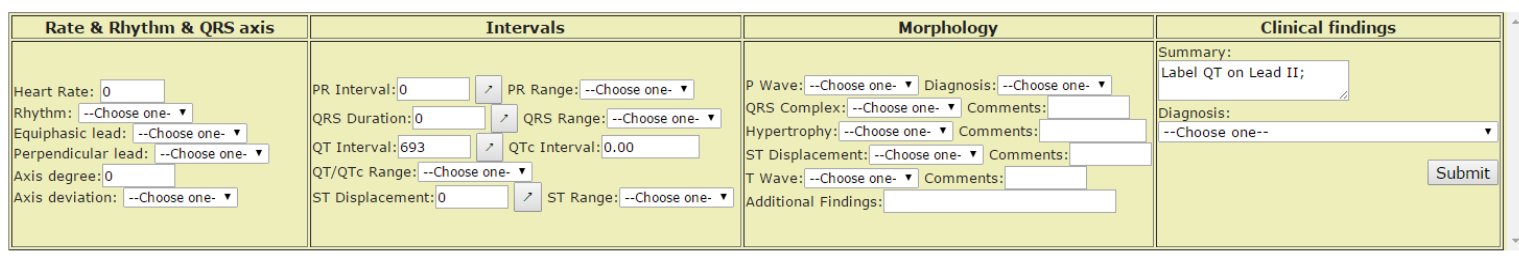

(b)

Figure 3: A demonstration for labelling the QT interval. The "Capture" button can be used to capture the highlighted interval as shown in (a). The interface automatically calculates the numerical values of the QT interval and stores it directly in the ECG report as shown in (b). The report also tracks a summary from user as shown in the "Summary" field.

In the training period, each submitted diagnosis of an ECG record was followed by an automatic feedback of the submission provided in the interface to enhance the learning experience as shown in Figure 4.

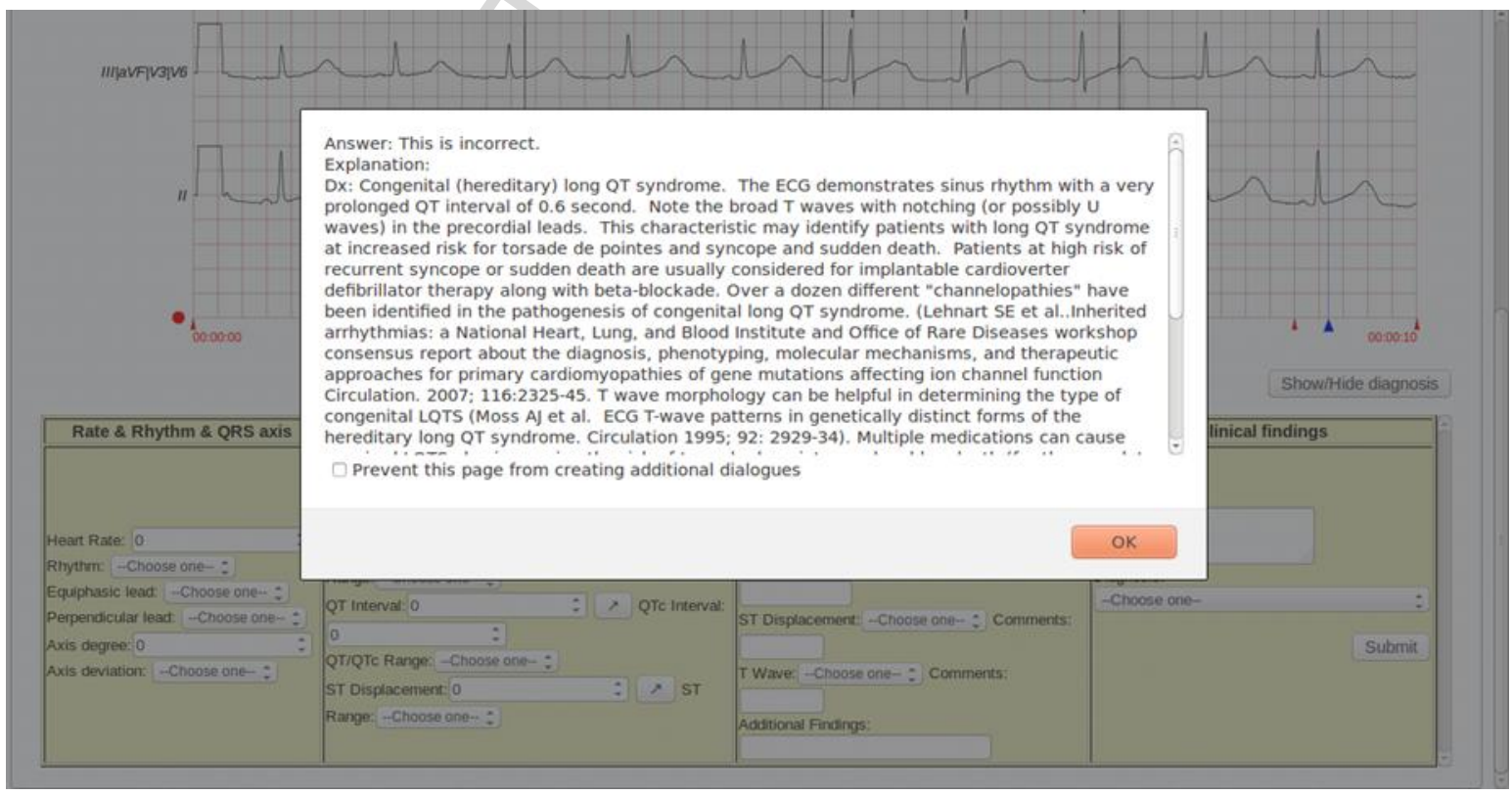

Figure 4: A screenshot of a dialog box indicating whether the submitted diagnosis is correct or not. A detailed explanation of the reason for the diagnosis was also provided. 
To avoid collusion among the students but also to ensure all students have practised with similar ECGs each week, 10 ECGs were allocated for each week corresponding to the teaching materials. Each student was given a subset of the 10 ECGs in a randomised order per week during the training period. In each consecutive week, we included 3 ECGs randomly chosen from the previous week practised by the individual student, and 7 ECGs from the 10 ECGs assigned for the week. During the test (week 7), we tested each student with 10 ECGs randomly selected from those that he/she was assigned in the previous 6 weeks to ensure that students were tested only on those ECGs on which they had previously practiced during the course.

\section{USER BEHAVIOUR AND PERFORMANCE DATA COLLECTION:}

Qualitative data of participants experience using the ECG training interface was collected through a questionnaire. A total of ten questions, which incorporated Likert scales and comments boxes were disseminated following completion of the study (figure 5). The diagnoses were submitted by the students during the training period (week 1 to 6 ) in a voluntary manner to assist them to learn the module materials using an interacting interface. A further test (week 7) was performed to examine the students' understanding of the materials learned throughout the course by judging if they have provided the correct diagnosis if given a 12-lead ECG recording. All data were collected in the interface and then stored in a secure server for analysis.

Statistics were generated and calculated using Microsoft Excel. Correlations were calculated using Cohen's effect size (d values) and Pearson's Product Moment Correlation Coefficient (r). Statistical significance testing was calculated using student $t$ test or Mann Whitney $U$ test where appropriate with a significance value of 
$p<0.05$. Statistics are presented in mean and median formats with standard deviation (s.d.) and/or interquartile ranges (IQR).

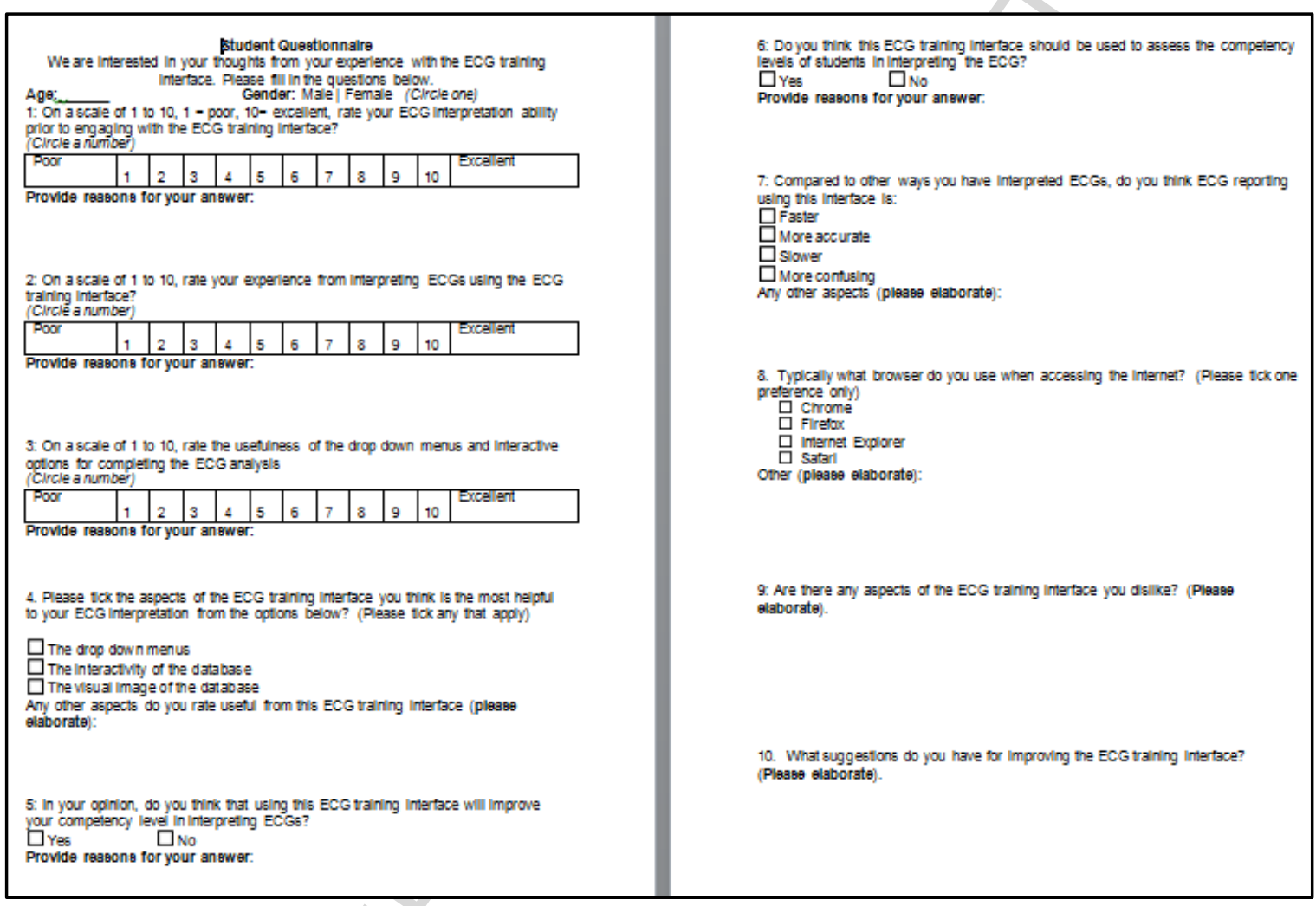

Figure 5. Qualitative data of participants experience using the ECG training interface was collected through a questionnaire which incorporated Likert scales and comments boxes

\section{RESULTS}

All participants performed ECG analysis using the CrowdLabel training interface. In the training period (weeks 1-6), each student was provided 10 ECGs individually and a total of 60 ECGs per student should have been submitted. Table 2 demonstrates the actual number of submissions/interpretations provided by students over the 6 weeks. 
Table 2: The number of ECGs practised by each student in a voluntary manner using the ECG training interface. The score was calculated using as a percentage of the ratio of the correct and submitted diagnoses. Note: These submissions include repeated ECGs which were provided in previous weeks.

\begin{tabular}{|c|c|c|c|}
\hline \multicolumn{4}{|c|}{ Training period (week 1 to 6 ) } \\
\hline Subject ID & $\begin{array}{l}\text { No. of } \\
\text { submitted } \\
\text { ECGs }\end{array}$ & $\begin{array}{l}\text { No. of correct ECG } \\
\text { diagnoses }\end{array}$ & Accuracy (\%) \\
\hline 1 & 6 & 1 & 16.7 \\
\hline 2 & 56 & 32 & 57.1 \\
\hline 3 & 7 & 2 & 28.6 \\
\hline 4 & 11 & 4 & $y$ \\
\hline 5 & 29 & 13 & $\longrightarrow$ \\
\hline 6 & 12 & 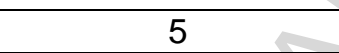 & 41.7 \\
\hline 7 & 14 & 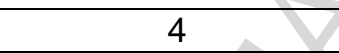 & 28.6 \\
\hline 8 & 93 & +1 & 43 \\
\hline 9 & 1 & 0 & 0 \\
\hline 10 & 7 & 2 & 28.6 \\
\hline 12 & 50 & 26 & 52 \\
\hline 13 & 1 & 0 & 0 \\
\hline 14 & 5 & 2 & 40 \\
\hline 15 & 27 & 7 & 25.9 \\
\hline 16 & 42 & 16 & 38.1 \\
\hline Median & 12 & 4 & 36.4 \\
\hline IQR & 29 & 12.5 & 15.1 \\
\hline MEAN & 24.1 & 21.2 & 32.1 \\
\hline S.D. & 26.1 & 18.3 & 16.7 \\
\hline
\end{tabular}

Out of 45 unique records provided to the 16 students, a total of 245 unique ECG cases were submitted by each student (see Table 3). Notice that student 1 submitted 6 diagnoses from 6 unique ECG records. Similar situations apply to student 9, 13 and 14. Hence their submitted number of ECGs was the same as those provided in Table 1. Accuracy was generally low (median accuracy 33.3\%), although the span of results was large (with accuracy ranging from $0 \%$ to $59.5 \%$ ). 
Table 3. The number of unique ECGs interpreted by each student in a voluntary manner using the ECG training interface. The score was calculated using as a percentage of the ratio of the correct and submitted diagnoses.

\begin{tabular}{|l|c|c|r|}
\hline Training period (week 1 to 6) & \multicolumn{2}{l|}{$\begin{array}{l}\text { Accuracy } \\
\text { (\%) }\end{array}$} \\
\hline $\begin{array}{l}\text { Subject } \\
\text { ID }\end{array}$ & No. of submitted ECGs & $\begin{array}{l}\text { No. orrect ECG } \\
\text { diagnoses }\end{array}$ & 16.7 \\
\hline 1 & 6 & 1 & 56.4 \\
\hline 2 & 39 & 22 & 33.3 \\
\hline 3 & 6 & 2 & 33.3 \\
\hline 4 & 9 & 3 & 50 \\
\hline 5 & 22 & 11 & 14.3 \\
\hline 6 & 7 & 1 & 50 \\
\hline 7 & 8 & 4 & 52.6 \\
\hline 8 & 38 & 20 & 0 \\
\hline 9 & 1 & 0 & 33.3 \\
\hline 10 & 6 & 2 & 59.5 \\
\hline 12 & 37 & 22 & 0 \\
\hline 13 & 1 & 0 & 40 \\
\hline 14 & 5 & 2 & 25 \\
\hline 15 & 20 & 5 & 40 \\
\hline 16 & 40 & 16 & $\mathbf{3 3 . 3}$ \\
\hline Median & $\mathbf{8}$ & $\mathbf{3}$ & $\mathbf{2 9 . 2}$ \\
\hline IQR & $\mathbf{2 3 . 5}$ & $\mathbf{1 2}$ & $\mathbf{3 3 . 6}$ \\
\hline Mean & $\mathbf{1 6 . 3}$ & $\mathbf{7 . 4}$ & $\mathbf{1 9 . 2}$ \\
\hline S.D. & $\mathbf{1 4 . 9}$ & $\mathbf{8 . 4}$ & \\
\hline
\end{tabular}

Table 4. The number of ECGs completed in a CrowdLabel test at week 7 . The score was calculated using as a percentage of the ratio of the correct and submitted diagnoses. Median score results and median number of answered items were compared to the module O.S.C.E. assessment results completed at week 9 (Mann Whitney $U=20, Z$ score $=-3.82, p<0.01$ ) and the official module examination results completed at week 16 (Mann Whitney $U=21, Z$ score $=-3.77, p<0.01$ ). 


\begin{tabular}{|l|c|c|c|c|c|}
\hline \multicolumn{2}{|l|}{ Assessment } \\
\hline $\begin{array}{l}\text { Subject } \\
\text { ID }\end{array}$ & $\begin{array}{l}\text { No. of } \\
\text { submitted } \\
\text { ECGs }\end{array}$ & $\begin{array}{l}\text { No. of correct } \\
\text { ECG diagnoses }\end{array}$ & $\begin{array}{l}\text { Test Score } \\
\text { (\%) week 7 }\end{array}$ & $\begin{array}{l}\text { Module } \\
\text { OSCE } \\
\text { Score (\%) } \\
\text { week 9 }\end{array}$ & $\begin{array}{l}\text { Module } \\
\text { Exam } \\
\text { Score (\%) } \\
\text { week 16 }\end{array}$ \\
\hline 1 & 10 & 5 & 50 & 54 & 67 \\
\hline 2 & 10 & 6 & 60 & 82 & 71 \\
\hline 3 & 10 & 3 & 30 & 63 & 77 \\
\hline 4 & 10 & 3 & 30 & 71 & 66 \\
\hline 5 & 8 & 3 & 37.5 & 68 & 63 \\
\hline 6 & 10 & 3 & 30 & 60 & 61 \\
\hline 7 & 10 & 5 & 50 & 66 & 56 \\
\hline 8 & 9 & 3 & 33.3 & 65 & 54 \\
\hline 9 & 10 & 3 & 30 & 83 & 78 \\
\hline 10 & 10 & 7 & 70 & 75 & 73 \\
\hline 12 & 10 & 5 & 50 & 84 & 77 \\
\hline 13 & 10 & 4 & 40 & 69 & 67 \\
\hline 14 & 10 & 3 & 30 & 62 & 61 \\
\hline 15 & 10 & 3 & 30 & 60 & 55 \\
\hline 16 & 10 & 7 & 70 & 80 & 72 \\
\hline Median & $\mathbf{1 0}$ & $\mathbf{3}$ & $\mathbf{3 7 . 5}$ & $\mathbf{6 8}$ & $\mathbf{6 7}$ \\
\hline IQR & $\mathbf{0}$ & $\mathbf{2}$ & $\mathbf{2 0}$ & $\mathbf{1 5}$ & $\mathbf{1 1 . 5}$ \\
\hline Mean & $\mathbf{9 . 8}$ & $\mathbf{4 . 2}$ & $\mathbf{4 2 . 7}$ & $\mathbf{6 9 . 5}$ & $\mathbf{6 6 . 5}$ \\
\hline S.D. & $\mathbf{0 . 6}$ & $\mathbf{1 . 5}$ & $\mathbf{1 4 . 7}$ & $\mathbf{9 . 4}$ & $\mathbf{8 . 1}$ \\
\hline
\end{tabular}

The findings from the CrowdLabel test (week 7) demonstrated variable ECG interpretation competency (Table 4). Accuracy scores during the training period ranged from $0-59.5 \%$ with a median accuracy score of $33.3 \%$. Conversely accuracy scores during the test ranged from $30-70 \%$ with a median value of $37.5 \%$ indicating that there was an improvement although not statistically significant (Median $=4.2$, Mann Whitney $U=93.5, Z$ Score $=-0.77, p<0.05)$. The accuracy scores from the coursework (OSCE) and examination aspect of the academic module were significantly improved by comparison, with marks ranging from $54-82 \%$ (Median 68\%) (Mann Whitney $\mathrm{U}=20, \mathrm{Z}$ score $=-3.82, \mathrm{p}<0.01)$ and $54-77 \%($ Median $67 \%)$ (Mann Whitney $U=21, Z$ score $=-3.77, p<0.01)$, Cohen's effect size value $(d=2.2)$ suggested a high practical significance. 
From tables 3 and 4 it can be seen that there is no correlation between those students who interpreted high numbers of ECGs during the training period and their marks obtained from the CrowdLabel test, coursework O.S.C.E. and examination of this academic module than those participants who interpreted lower numbers of ECGs (Pearson's Product Moment Correlation Coefficient, $r=0.39$, $r=0.43$ and $r=-$ 0.02).

\section{SURVEY FINDINGS}

Each participant provided feedback on their experience of using the ECG training interface by completing a questionnaire (figure 5). The usefulness of the ECG training interface was rated highly (median $=8, I Q R=1$ ), mostly due to its interactivity. Participants rated the drop down menu option most favourably $(n=12$, $80 \%)$ stating that this format enabled them to interpret an ECG faster ( $n=11,73 \%)$ and more accurately $(n=5,33 \%)$. Participants stated that using the ECG training interface would improve their competence interpreting ECGs $(n=15,100 \%)$ and agreed that the ECG training interface should be adopted into the curriculum of this

topic $(n=11,73 \%)$. Prior to completing the interpretation task participants rated their ability to interpret an ECG as low (median $=3, I Q R=2.75$ ) (see table 5). 
Table 5. The findings collected from the student feedback questionnaire.

\begin{tabular}{|c|c|}
\hline Question & Answer \\
\hline $\begin{array}{l}\text { 1: On a scale of } 1 \text { to } 10,1=\text { poor, } 10=\text { excellent, rate your ECG } \\
\text { interpretation ability prior to engaging with the ECG training ECG } \\
\text { training interface? }\end{array}$ & $\begin{array}{l}\text { median }=3(\mathrm{IQR}= \\
2.75)\end{array}$ \\
\hline $\begin{array}{l}\text { 2: On a scale of } 1 \text { to } 10 \text {, rate your experience from interpreting } \\
\text { ECGs using the ECG training ECG training interface? }\end{array}$ & $\begin{array}{l}\text { median }=6(\mathrm{IQR}= \\
\text { 3.5) }\end{array}$ \\
\hline \multirow{2}{*}{$\begin{array}{l}\text { 3: On a scale of } 1 \text { to } 10 \text {, rate the usefulness of the drop down } \\
\text { menus and interactive options for completing the ECG analysis } \\
\text { 4. Please tick the aspects of the ECG training ECG training interface } \\
\text { you think is the most helpful to your ECG interpretation from the } \\
\text { options below? }\end{array}$} & $\begin{array}{l}\text { median }=8(\mathrm{IQR}= \\
\text { 1) }\end{array}$ \\
\hline & \\
\hline The drop down menus & $12(80 \%)$ \\
\hline The interactivity of the database & $6(40 \%)$ \\
\hline The visual image of the database & $5(33 \%)$ \\
\hline $\begin{array}{l}\text { 5: In your opinion, do you think that using this ECG training ECG } \\
\text { training interface will improve your competency level in interpreting } \\
\text { ECGs? }\end{array}$ & $\begin{array}{l}\text { YES, } n=15(100 \%) \\
\text { N0, } n=0(0 \%)\end{array}$ \\
\hline $\begin{array}{l}\text { 6: Do you think this ECG training ECG training interface should be } \\
\text { used to assess the competency levels of students in interpreting the } \\
\text { ECG? }\end{array}$ & $\begin{array}{l}\text { YES, } n=11,(73 \%) \\
\text { N0, } n=4(26 \%)\end{array}$ \\
\hline \multicolumn{2}{|l|}{$\begin{array}{l}\text { 7: Compared to other ways you have interpreted ECGs, do you } \\
\text { think ECG reporting using this ECG training interface is: }\end{array}$} \\
\hline Faster & $11(73 \%)$ \\
\hline More accurate & $5(33 \%)$ \\
\hline Slower & $3(20 \%)$ \\
\hline More confusing & $2(13.3 \%)$ \\
\hline \multicolumn{2}{|l|}{$\begin{array}{l}\text { 8. Typically what browser do you use when accessing the internet? } \\
\text { (Please tick one preference only) }\end{array}$} \\
\hline Chrome & $14(93 \%)$ \\
\hline Firefox & $0(0 \%)$ \\
\hline \multirow{2}{*}{$\begin{array}{l}\text { Internet Explorer } \\
\text { Other }\end{array}$} & $1(6.7 \%)$ \\
\hline & $0(0 \%)$ \\
\hline
\end{tabular}

\section{Discussion:}

A review of teaching methods for the interpretation of ECGs identified no standard method for ECG interpretation acquisition teaching (9). Indeed, the literature illustrates faculty training and teaching format varies considerably $(1,9-18)$. The findings from this study demonstrate ECG interpretation is best accomplished by the incorporation of a blended pedagogy consisting of didactical and e learning formats evaluated through summative assessment. These findings complement the work of 
Jang et al, 2005 (1) and Patuwo et al, 2007 (17) who found that computer-assisted instruction was as effective as traditional classroom lecture but that the combination of Web-based and lecture based learning was more effective than either strategy used alone (17).

ECG interpretation requires knowledge of the pathophysiology of ECG abnormalities, the ability to visually interpret common abnormal ECG patterns, and experience aligning the ECG interpretation to a patient's scenario (24) prior to proficiency. The CrowdLabel interface provides learners with an active and dynamic environment for learning specific to this outcome. Active learning instruction is defined as strategies that involve learners doing things, giving students the opportunity to experiment or interact with learning tools so to develop their competencies (12). The learning and teaching strategy integrated within the academic module CP1ECG must be identified as robust and reliable. Participants demonstrated high accuracy scores for ECG interpretation during the O.S.C.E. coursework and official module examination results, informing that the teaching format supporting ECG interpretation to HCSPs impacts positively to the knowledge acquisition of this clinical skill.

As identified in the literature, there is no evidence-based data available and conflicting expert recommendations on how many ECG interpretations are needed to obtain initial ECG competency. Salerno et al. (27) states given the lack of evidencebased literature, the number of ECGs required to achieve initial competency in ECG interpretation should be based on objective assessment and periodic documentation of ECG interpretation skills rather than completion of a minimum number of interpretations, a finding which complements the outcomes of this study. 


\section{Conclusion and Future work:}

The utility of the ECG in clinical decision making depends on the effectiveness with which the principles and interpretive techniques of ECG are learned. Additional resources to support ECG interpretation are welcome and necessary to meet the outcomes of its mastery and that feedback on a learner's progress. The results show that, for the ECGs chosen in this evaluation, during a learning period a trainee may have a low accuracy for ECG interpretation but pass the curriculum via an academic examination. A limitation of this study was the relatively small sample size recruited these participating students might have been motivated more highly to study than the average students of the college who could have participated in this study..

Future work will focus on redeploying the web interface to a cloud based system to ensure its scalability for large number of users. As a demonstration of the possibility of integrating a low resource JavaScript based ECG training interface and a standardised curriculum for self-guided tuition in ECG diagnosis, CrowdLabel is shown to be a readily accessible dedicated learning platform to support ECG interpretation competency.

\section{Acknowledgement:}

XX acknowledges the support of the RCUK Digital Economy Programme grant number EP/G036861/1 and an ARM Scholarship in Sustainable Healthcare Technology through Kellogg College, the University Oxford. 


\section{References}

1 - PATUWO, T.P., WAGNER, G.S. and AJIJOLA, O.A., 2007. Comparison of Teaching Basic Electrocardiographic Concepts with and without ECGSIM, an Interactive Program for Electrocardiography. Computers in Cardiology 2007, Vol 34, 34, pp. 61-64.

2 - Balady GJ, Bufalino VJ, Gulati M, Kuvin JT, Mendes LA, Schuller JL. COCATS 4 task force 3: training in electrocardiography, ambulatory electrocardiography, and exercise testing. J Am Coll Cardiol 2015;65:1763-77.

3 - Kligfield P., Gettes L.S., Bailey, J.J., Childers, R., Deal, B.J., Hancock, W., van Herpen, G., Jors, J.A., Macfarland, P., Mirvis, D.M, Pahlm, O., Rautaharju, P. and Wagner, G.S. Recommendations for the standardization and interpretation of the electrocardiogram. Part I: the electrocardiogram and its technology: a scientific statement from the American Heart Association Electrocardiography and Arrhythmias Committee, Council on Clinical Cardiology; the American College of Cardiology Foundation; and the Heart Rhythm Society. J Am Coll Cardiol 2007;49:1109-27.

4 - Mason JW, Hancock EW, Gettes LS. Recommendations for the standardization and interpretation of the electrocardiogram. Part II: electrocardiography diagnostic statement list: a scientific statement from the American Heart Association Electrocardiography and Arrhythmias Committee, Council on Clinical Cardiology; the American College of Cardiology Foundation; and the Heart Rhythm Society. J Am Coll Cardiol 2007;49:1128-35.

5 - Surawicz B, Childers R, Deal BJ and Gette, L.S., 2009. AHA/ACCF/HRS recommendations for the standardization and interpretation of the electrocardiogram. Part III: intraventricular conduction disturbances: a scientific statement from the American Heart Association Electrocardiography and Arrhythmias Committee, Council on Clinical Cardiology; the American College of Cardiology Foundation; and the Heart Rhythm Society. J AmColl Cardiol 2009;53:976-81.

\section{6 - Rautaharju PM, Surawicz B and Gettes LS, 2009. AHA/ACCF/HRS}

recommendations for the standardization and interpretation of the electrocardiogram. Part IV: the ST segment, T and U waves, and the QT interval: a scientific statement from the American Heart Association Electrocardiography and Arrhythmias Committee, Council on Clinical Cardiology; the American College of Cardiology Foundation; and the Heart Rhythm Society. J Am Coll Cardiol 2009;53:982-91.

7 - Hancock EW, Deal BJ, Mirvis DM, Okin, P., Kligfield, P. and Gettes, L.S., 2009. AHA/ACCF/HRS recommendations for the standardization and interpretation of the electrocardiogram. Part V: electrocardiogram changes associated with cardiac chamber hypertrophy: a scientific statement from the American Heart Association Electrocardiography and 
Arrhythmias Committee, Council on Clinical Cardiology; the American College of Cardiology Foundation; and the Heart Rhythm Society. J Am Coll Cardiol 2009;53:992-1002.

8 - Wagner GS, Macfarlane P, Wellens H, Josephson, M., Gorgels, A., Mirvis, D.M., Pahlm, O., Surawicz, B., Kligfield, P., Childers, R. and Gettes, L.S., 2009.

AHA/ACCF/HRS recommendations for the standardization and interpretation of the electrocardiogram. Part VI: acute ischemia/infarction: a scientific statement from the American Heart Association Electrocardiography and Arrhythmias Committee, Council on Clinical Cardiology; the American College of Cardiology Foundation; and the Heart Rhythm Society. J Am Coll Cardiol 2009;53:1003-11.

9 - Fent, G., Gosai, J. and Purva, M., 2015. Teaching the interpretation of electrocardiograms: Which method is best? Journal of Electrocardiology, Vol 48, pp. 190 - 193.

10 - Auseon, A.J., 2009. Methods of teaching and evaluating electrocardiogram interpretation skills among cardiology fellowship programs in the United States. Journal of Electrocardiology, Vol 42, pp. 339-344.

11 - Montgomery, H., Hunter, S., Morris, S., Naughton-Morgan, R. \& Marshall, R.M., 1994. Interpretation of electrocardiograms by doctors. British Medical Journal. 309: 1551-2.

12 - Criley, J.M. \& Nelson, W.P., 2006. Virtual tools for teaching electrocardiographic rhythm analysis. Journal of Electrocardiography. 39; 113-119.

13 - Mahler, S.A., Wolcott, C.J., Swoboda, T.K., Wang, H. \& Arnold, T.C., 2011. Techniques for teaching electrocardiogram interpretation: self-directed learning is less effective than a workshop or lecture. Medical Education 45: 347-353

14 - Nilsson, M., Bolinder, G., Held, C., Johansson, B.L., Fors, U. \& Ostergren, J., 2008. Evaluation of a web-based ECG-interpretation programme for undergraduate medical students. BMC Medical Education. 8:25.

15 - Rubinstein, J., Dhoble, A. \& Ferenchick, G., 2009. Puzzle based teaching versus traditional instruction in electrocardiogram interpretation for medical students - a pilot study. BMC Medical Education 9:4.

16 - Nilsson et al.: Does individual learning styles influence the choice to use a webbased ECG learning programme in a blended learning setting? BMC Medical Education 2012 12:5.

17 - JANG, K.S., HWANG, S.Y., PARK, S.J., KIM, Y.M. and KIM, M.J., 2005. Effects of a Web-based teaching method on undergraduate nursing students' learning of electrocardiography. Journal of Nursing Education, 44(1), pp. 35-39. 
18 - MAHLER, S.A., WOLCOTT, C.J., SWOBODA, T.K., WANG, H. and ARNOLD, T.C., 2011. Techniques for teaching electrocardiogram interpretation: self-directed learning is less effective than a workshop or lecture. Medical education, 45(4), pp. 347-353.

19 - ANON, 2011. MODERNISING SCIENTIFIC CAREERS, Practitioner Training Programme, BSc (Hons) Healthcare Science, Work Based Training Learning Guide. Available: http://www.networks.nhs.uk/nhs-networks/mscframeworkurricula/documents/BSc HCS Cardiovascular Respiratory Sleep Scienc e\%202011-12.pdf (accessed 04/03/2015).

20 - Academy for Healthcare Science, What Healthcare Science Practitioners do. Available: http://www.ahcs.ac.uk/about-us/about-healthcare-science/healthcarescience-practitioners/ (accessed 04/03/2015)

21 - Tingting Zhu, Joachim Behar, Tasos Papastylianou, Gari D Clifford, "CrowdLabel: A crowdsourcing platform for electrophysiology," Computing in Cardiology Conference (CinC), 2014 , vol.41, pp.789-792, 2014.

22 - Goldberger AL, Amaral LAN, Glass L, Hausdorff JM, Ivanov PCh, Mark RG, Mietus JE, Moody GB, Peng C-K, Stanley HE., 2000. PhysioBank, PhysioToolkit, and PhysioNet: Components of a New Research Resource for Complex Physiologic Signals. Circulation 101(23):e215-e220

[Available: Circulation Electronic Pages;

http://circ.ahajournals.org/cgi/content/full/101/23/e215 (accessed 04/03/2015).

23 - Nathanson, L. A., Safran, C., McClennen, S., \& Goldberger, A. L., 2001. ECG Wave-Maven: a self-assessment program for students and clinicians. Proceedings / AMIA ... Annual Symposium. AMIA Symposium, 488-92. Available:

http://ecg.bidmc.harvard.edu/maven/mavenmain.asp (accessed 04/03/2015).

24 - Sibbald, M., 2014. Training/Practice: Training Electrocardiographic Interpretation Skills of Cardiology Residents: Are They Competent? Canadian Journal of Cardiology, Vol 30, pp. 1721 - 1724.

25 - ECG report sheet. Society for Cardiological Science and Technology (SCST) http://www.scst.org.uk/resources/5C1 ECG report sheet 2006.pdf (accessed 04/03/2015).

26 - ECG Wave-Maven, a self-assessment programme for clinicians and students available http://ecg.bidmc.harvard.edu/maven/mavenmain.asp (accessed 10/09/2015).

27 - Salerno, S.M., Alguire, P.C. \& Waxman, H.S., 2003. Training and Competency Evaluation for Interpretation of 12-Lead Electrocardiograms: Recommendations from the American College of Physicians. American College of Physicians Journal 138:747-750. 